\title{
Annotations
}

\section{Surgery for epilepsy}

\section{Introduction}

The current uptake of surgical treatment for drug resistant epilepsy in most countries in the western world is probably far too low. There are few centres whose practice in epilepsy surgery is limited to children. The number of patients operated upon, even in centres with a mixed practice, is relatively small; an exception is Montreal. Therefore, except where specifically indicated, the material referred to includes adult patients. Using adult figures it is thought for example that in the United States there are 360000 patients with poorly controlled partial epilepsies and that perhaps 7500 of these would be suitable for surgical treatment. ${ }^{1}$ A recent survey of 25 units working over many years yielded only 2500 operations over the whole of the western world. ${ }^{2}$

There are two means by which a surgical operation can abolish epileptic seizures or reduce their frequency. The first is by treating focal brain pathology, which is not necessarily as easy as it seems because the pathology may be hard to demonstrate or it may be difficult to link such pathology directly with the patient's seizures. The second is to influence brain function in some way to prevent or restrict the propagation of the epileptic discharge. Many operations are hybrid in nature involving the application of both premises. The more successful and commoner resective surgery involves mostly the removal of pathology, although the removal of local brain tissue is also involved. By contrast operations employing the second premise are much rarer and on the whole less successful.

\section{Selection}

Basic clinical skills are important to elicit the history of an appropriate event such as a febrile convulsion or unilateral hemisphere disease or by exclusion some other brain abnormality such as a hamartoma; this was shown elegantly by Ounstead and colleagues many years ago. ${ }^{3}$ The same skills are needed to elicit the consistency of seizure pattern which may indicate a possible focal origin for them. Finally enquiry into the child's intellectual and behavioural status is needed. Except in cases of obvious cerebral damage, or a progressive lesion, neurological signs are rare in these patients.
Brain imaging and neuropsychological and neurophysiological investigations of varying degrees of complexity are needed. There are a variety of methods of brain imaging available: a combination of high quality brain scans by computed tomography and magnetic resonance imaging will show lesions such as arteriovenous malformations, hamartomas, and slow growing glial tumours in over $95 \%$ of cases, but are less adept at showing processes such as mesial temporal sclerosis in the temporal lobe. ${ }^{4}$ Functional methods of brain imaging such as positron emission tomography and single photon emission computed tomography are not presently useful for routine investigation. ${ }^{5}$

Neuropsychology is important both to assess the present intellectual function and to predict the possible consequences of cerebral function. The absence of proper 'norms' in this population introduces some difficulties.

Neurophysiological investigation needs special techniques and personnel even in adults. With patients, however, many of these techniques, including the newer ones such as foramen ovale telemetering ${ }^{6}$ and subdural mat recording, ${ }^{7}$ can be applied to children. Videotelemetry with adequate neurophysiological recording can be used to demonstrate focal seizure onset and is also important where the nature and consistency of the seizure onset is an issue. It should not be confused with cassette ambulatory monitoring, which will only indicate the occurrence and frequency of seizures but not their nature or origin.

\section{Resective operations}

Operations on the temporal lobe are still the most frequently performed for the relief of seizures, and the recent introduction of selective amygdalohippocampectomy enables the surgeon, in appropriate cases, to achieve the maximum chance of the control of epilepsy with the minimal risk of cerebral damage. ${ }^{8}$ Falconer and Davidson showed that similar results with regard to seizure relief and social improvement were seen in children as in adults. ${ }^{9}$ In a recent series of 50 children from the Mayo clinic $78 \%$ were rendered fit free by temporal lobectomy. ${ }^{10}$ Matching the operation to the patient is a complex process described in a recent review. ${ }^{11}$ In terms of 
seizure control alone such operations have a wide range of success, varying from $26 \%$ to $80 \%$ seizure free across 2336 patients operated upon in 40 centres. ${ }^{2}$ The reason for this wide variation probably lies in patient selection and the mix of pathology in each centre rather than variations in surgical technique. There are other benefits in terms of behaviour and life adaptation when such an operation is successful as emphasised by Taylor and Falconer ${ }^{12}$ and a recent study from the Park Hospital. ${ }^{13}$

Extratemporal operations-mostly frontal lobe resections - can be equally successful as shown by the Montreal results where $35 \%$ of a mixed group of adults and children were fit free. ${ }^{14}$ Another recent review indicates an average fit free rate of $43 \%$ in extratemporal resections in 825 patients from 32 centres. $^{2}$

Major resections, by which is meant removal of several lobes or most or all of the cerebral hemisphere, are often undervalued because of a natural fear of the size and effect of the resection. These are only undertaken, however, in patients with a substantial physical handicap often accompanied by a considerable intellectual deficit and should not be undertaken if there is any risk of substantially increasing the patient's physical or intellectual problems. If this is avoided by appropriate selection, then the benefits of improved seizure control and resolution of behavioural difficulties is often considerable and will benefit both the patient and those who have to care for the child. Total hemispherectomy acquired a bad reputation because of the complication of late delayed bleeding. ${ }^{15}$ However, there are two modifications of the classical surgical technique to avoid the problem. One from Montreal, in which the removal is anatomically subtotal but made functionally total by complete callosotomy, makes $83 \%$ of patients seizure free over periods of three to 28 years. ${ }^{16}$ The other described by Beardsworth and Adams modifies the closure after anatomically complete removal and can be expected to give the same seizure relief as classical hemispherectomy, which is about $80 \%$ fit free. A recent look at the results of this procedure shows it to be efficient and complication free. ${ }^{17}$

\section{Functional operations}

At present the creation of discrete lesions in various deep brain structures, including the mesial temporal structures, by stereotactic means is little employed, less described, and regarded by most authors as inefficient. ${ }^{18} 19$

The operation of callosal section is undergoing a resurgence. Careful selection of candidates, the use of microsurgical techniques, and restriction of the section to the anterior two thirds of the corpus callosum, have minimised many of the complications associated with the early use of the operation: In a recent review Williamson suggested that it could be used in two groups of patients. ${ }^{20}$ The first group have unilateral hemisphere disease and might otherwise be suitable for hemispherectomy. In this group $75 \%$ of the patients achieve an $80 \%$ reduction in their seizure frequency. The second group were patients with generalised epilepsies such as LennoxGastaut syndrome in which the operation was useful but less effective producing an $80 \%$ reduction in seizure frequency in $50 \%$ of patients. ${ }^{20}$

In a few patients, such as those with Rasmussen's disease,$^{21}$ a situation may develop in which focal seizures emanate from an area of eloquent cortex whose resection would introduce an unacceptable neurological deficit. An elegant solution to this situation has been proposed by Morrell in which the horizontal cortical connections which allow propagation of the epileptic discharge are destroyed but the vertical fibres by which voluntary movement is initiated are preserved. ${ }^{22}$ This procedure of multiple cortical subpial transection has produced good results in a small series.

\section{Conclusion}

This annotation is necessarily a brief and uneven summary of the present position. Detailed and more complete information is to be found in recent review articles and books. ${ }^{23-25}$

\section{References}

1 Dreifuss FE. Goals of surgery. In: Engel J, ed. Surgical treatment of the epilepsies. New York: Raven Press, 1987:31-49.

2 Engel J. Outcome with respect to epileptic seizures. In: Engel J, ed. Surgical treatment of the epilepsies. New York: Raven Press, 1987:553-71.

3 Ounstead C, Lindsay J, Norman J. Biological factors in temporal lobe epilepsy. London: Heinemann, 1966.

4 Sperling MR, Wilson G, Engel J, Babb TL, Phelps M, Bradley W. Magnetic resonance imaging in intractable partial epilepsy: correlative studies. Ann Neurol 1986;20:57-62.

5 Sperling MR, Sutherling WW, Nuwer M. New techniques for evaluating patients for epilepsy surgery. In: Engel J, ed. Surgical treatment of the epilepsies. New York: Raven Press, 1987:235-55.

6 Wieser HG, Elger CF, Stodieck SRG. The 'Foramen Ovale Electrode': a new recording method for pre-operative evaluation of patients suffering from medio-basal temporal lobe epilepsy. Electroencephalography and Clinical Neurophysiology 1985; 61:314-22.

7 Goldring S, Gregorie EM. Surgical management of epilepsy using epidural mats to localise the seizure focus. Review of 100 cases. J Neurosurg 1984;60:457-66.

8 Wieser HG. 'Selective amygdalohippcampectomy': indications, investigative technique and results. In: Symon L, ed. Advances and technical standards in neurosurgery. Vol 13. Vienna: Springer Verlag, 1985:39-133.

9 Falconer MA, Davidson S. The rationale of surgical treatment of temporal lobe epilepsy with particular reference to childhood 
and adolescence. In: Harris P, Mawdsley C, eds. Epilepsy. Proceedings of the Hans Berger centenary symposium. Edinburgh: Churchill Livingstone, 1974:209-14.

${ }^{10}$ Meyer FB, Marsh WR, Laws ER, Sharbrough FW. Temporal lobectomy in children with epilepsy. $J$ Neurosurg 1986;64:371-7.

11 Polkey CE. Surgical alternatives for the treatment of temporal lobe epilepsy. British Journal of Neurosurgery 1988;2:143-52.

12 Taylor DC, Falconer MA. Clinical, socio-economic and psychological changes after temporal lobectomy for epilepsy. $\mathrm{Br} J$ Psychiatry 1966;114:1247-61.

13 Ounstead C, Lindsay J, Richards P. The neurosurgical option. In: Ounstead C, Lindsay J, Richards $\mathrm{P}$, eds. Temporal lobe epilepsy. A biographical study 1948-1986. Oxford: Blackwell Scientific Publications Ltd, 1987:51-8.

14 Rasmussen T. Surgery of frontal lobe epilepsy. In: Purpura DP, Penry JK, Walter RD, eds. Neurosurgical management of the epilepsies. Advances in neurology. Vol 8. New York: Raven Press, 1975:197-205.

15 Oppenheimer DR, Griffith HB. Persistent intracranial bleeding as a complication of hemispherectomy. Journal of Neurol Neurosurg Psychiatry 1966;29:229-40.

16 Rasmussen T. Cortical resection for multilobe epileptogenic lesions. In: Wieser HG, Elger CE, eds. Presurgical evaluation of epileptics. Berlin: Springer Verlag, 1987:344-51.

17 Beardsworth ED, Adams CBT. Modified hemispherectomy: early results in 10 cases. British Journal of Neurosurgery 1988;2:73-84.

18 Ojemann GA, Ward AA. Stereotactic and other procedures for epilepsy. In: Purpura DP, Penry JK, Walter RD, eds. Neuro- surgical management of the epilepsies. Advances in neurology. Vol 8. New York: Raven Press, 1975:241-63.

19 Spencer DD. Postscript: should there be a surgical treatment of choice, and if so, how should it be determined? In: Engel J, ed. Surgical treatment of the epilepsies. New York: Raven Press, 1987:477-84.

20 Williamson PD. Corpus callosum section for intractable epilepsy. In: Reeves AG, ed. Epilepsy and the corpus callosum. New York; Plenum Press, 1985:243-57.

${ }^{21}$ Rasmussen T. Further observations on the syndrome of chronic encephalitis and epilepsy. Appl Neurophysiol 1978;41:1-12.

22 Morrell F, Wisler WW, Bleck TP. Multiple subpial transection: a new approach to the surgical treatment of focal epilepsy. $J$ Neurosurg (in press).

${ }^{23}$ Flanigin HF, King D, Gallagher B. Surgical treatment of epilepsy. In: Pedley TA, Meldrum BS, eds. Surgical treatment of epilepsy. Edinburgh: Churchill Livingstone, 1985:517-59.

24 Engel J, ed. Surgical treatment of the epilepsies. New York: Raven Press, 1987.

25 Polkey CE. Neurosurgery. In: Laidlaw J, Richens A, Oxley J, eds. A textbook of epilepsy. Edinburgh: Churchill Livingstone, 1988:484-510.

C E Polkey Neurosurgical Unit, The Maudsley Hospital, De Crespigny Park, London SE5 8AZ 